\title{
Effects of human leukocyte antigen (HLA)-DR engagement on melanoma cells
}

\author{
GIOVANNA BARBIERI, EMILIO RIMINI and MARIA ASSUNTA COSTA
}

\author{
Istituto di Biomedicina e Immunologia Molecolare 'Alberto Monroy', Consiglio Nazionale \\ delle Ricerche (CNR), Via Ugo La Malfa 153, I-90146, Palermo, Italy
}

Received December 23, 2010; Accepted February 21, 2011

DOI: 10.3892/ijo.2011.988

\begin{abstract}
Melanoma cells often display constitutive expression of the major histocompatibility complex (MHC) class II molecules which is associated with a higher metastatic dissemination. The MHC class II molecules during T cell/ professional antigen-presenting cell (APC) interactions are localized, as signalling receptors, into membrane lipid rafts which are thought to be sites of signalling complex assembly. Therefore, with the aim of understanding the molecular mechanisms used by melanoma cells to frustrate an effective anti-tumour response we stimulated a MHC class II constitutive expressing melanoma cell line with a specific antibody that mimics the interaction of T-cell receptor (TCR) with class II molecules. In stimulated melanoma cells we showed through Western blotting and immunofluorescence experiments the recruitment of HLA-DR molecules in lipid raft compartments as well as the c-Jun $\mathrm{NH}_{2}$-terminal kinase activations as a consequence of the class II engagement. Furthermore, we showed that SDS-stable HLA-DR-peptide complexes are recruited in lipid rafts of stimulated melanoma cells. Therefore, in light of the results reported, our hypothesis is that the redistribution of class II molecules into lipid raft microdomains of stimulated melanoma cells as well as the associated activation of signalling pathways, could be useful for melanoma cells to frustrate an effective anti-tumour response.
\end{abstract}

\section{Introduction}

Melanoma arises from the malignant transformation of pigment producing cells or melanocytes. Indeed, melanoma is the cancer with the higher incidence in Western populations (1) and it is notoriously resistant to all current cancer therapy (2).

Correspondence to: Dr Giovanna Barbieri, Istituto di Biomedicina e Immunologia Molecolare 'Alberto Monroy', Consiglio Nazionale delle Ricerche (CNR), Via Ugo La Malfa 153, I-90146 Palermo, Italy

E-mail: barbieri@ibim.cnr.it

Key words: A375 melamoma cell line, MHC class II, lipid rafts, c-Jun $\mathrm{NH}_{2}$-terminal kinase
This lethal form of skin cancer has a high propensity to metastasize progressing through a radial growth phase and a vertical growth phase when melanoma cells penetrate both the upper layer of the epidermis and the underlying dermal layer (3). Interestingly, recent studies on patients with metastatic melanoma have shown infrequently spontaneous $\mathrm{T}$ cell responses (4-6) and primary melanoma regressions as well as sporadic spontaneous remissions of metastatic disease and favourable clinical upshots related to autoimmune disorders such as vitiligo $(7,8)$. The although uncommon immune responses to melanoma that these results clearly suggested have encouraged the development of immunotherapeutic approaches for melanoma (9-12). Unfortunately until now the immunotherapy used has limited success and only a modest number of patients showed objective responses. These results display the ability of melanoma cells to escape immune response and to alter the function and survival of immune cells. Therefore, new insights into the relationship between melanoma and the host immune response are required to overcome cancer immune evasion and subversion. Almost $20 \%$ of melanomas, in contrast to normal skin melanocytes, express the major histocompatibility complex class II (MHC class II) molecules and $50 \%$ of the metastatic lesions are class II positives, thus the constitutive MHC class II expression in melanoma is associated to disease progression and is linked to a poor prognosis (13-19). However, these tumour cells could act as antigen-presenting cells since the $\mathrm{CD}^{+} \mathrm{T}$ lymphocytes can recognize peptides complexed with the MHC class II molecules in melanoma (20-22). Nevertheless, melanoma cells can inhibit an effective immunotherapy through the selection of tumour variants undetectable by the immune system or actively suppressing the tumourreactive T-cell clones as was previously reported (23). The human leukocyte antigen (HLA)-DR is one of three highly polymorphic MHC class II genes which express two noncovalently associated transmembrane glycoproteins, the $\alpha$ - and $\beta$-chains, that are primarily expressed on B lymphocytes, monocytes, dendritic cells and thymic epithelial cells (24). In addition, interferon- $\gamma$ induces MHC class II expression in a wide variety of cell types, including endothelial cells, fibroblasts, epithelial cells and melanocytes $(24,25)$. The most widely recognized function of MHC class II molecules is the presentation of antigens to $\mathrm{T}$ lymphocytes but these molecules are also important signalling receptors. Signals mediated by the engagement of the MHC class II molecules have been shown to 
influence antigen-presenting function, adhesion, apoptosis, growth, differentiation and cytokine production of the antigenpresenting cells (APC) (26). In APCs both signalling and antigen presentation are greatly enhanced by the MHC class II molecule compartmentalization into specific microdomains of the plasma membrane called lipid rafts (27-29). The lipid rafts are dynamic membrane microdomains highly enriched in sphingolipids (sphingomyelin and glycosphingolipids) and cholesterol that are implicated in the selective protein-protein interactions as well as in the assembly of transient signalling platforms and more permanent structure such as the immunological synapse (30). Interestingly, in different tumour cell lines it has been reported that the signalling activated by the MHC class II molecules is associated to the lipid raft localization of these molecules $(31,32)$, but less knowledge is available in this field for melanoma. Therefore, in the aim to understand the molecular mechanisms used by melanomas to frustrate an effective anti-tumour response, we studied in a MHC class II constitutive expressing melanoma cell line (A375), the membrane localization and the functionality of the class II molecules as well as the MHC class II signalling. In particular, we showed the recruitment of the HLA-DR molecules in the lipid raft compartments of melanoma cells stimulated with a specific anti-HLA-DR monoclonal antibody (L243) that mimics the TCR interaction with the class II molecules (33). Then, we demonstrated the peptide binding of MHC class II $\alpha \beta$ heterodimers in A375 melanoma cells, as assessed by their SDS stability. We showed that the antigen presentation by the HLA-DR molecules compartmentalized into lipid raft. In this study we also reported an increasing c-Jun $\mathrm{NH}_{2}$-terminal kinase (JNK), but not p38 activation as a consequence of the HLA-DR engagement.

\section{Materials and methods}

Cell lines, antibodies and reagents. The highly invasive A375 melanoma cells (ATCC-CRL-1619) (34), were a kind gift of Professor C. Alcaide-Loridan. The cells were grown in RPMI-1640 supplemented with $10 \%$ FCS and 1\% penicillinstreptomycin $(10,000 \mathrm{U} / \mathrm{ml}$ and $10,000 \mu \mathrm{g} / \mathrm{ml}$, respectively) in $5 \% \mathrm{CO}_{2}$ at $37^{\circ} \mathrm{C}$. Monoclonal antibodies direct against the C-terminal intracellular tail of HLA-DR- $\alpha$-chain (DA6.147) (35) and against a conformational epitope of HLA-DR molecules (L243, mouse IgG2a) (33), were kindly given by Professor C. Alcaide-Loridan and were affinity purified from ascitic fluid using a protein G column (GE Healthcare, Biosciences, Buckinghamshire, UK). Polyclonal antibody direct against caveolin-1 was obtained from BD Transduction Laboratories (Lexington, KY). Polyclonal antibody direct against Phospho-SAPK/JNK (Thr183/Tyr185) was purchased from Cell Signaling Technology (Beverly, MA, USA). Anti-h$\beta$-actin monoclonal antibody, FITC and TRITC conjugated anti-mouse $\mathrm{IgG}$, the mouse $\mathrm{IgG} 2 \mathrm{a}$ isotype control $\mathrm{Ig}$, the cholera toxin B subunit FITC conjugated and the methyl-betacyclodextrin (MßCD) were purchased from Sigma (St. Louis, MO). HRP-conjugated anti-rabbit and HRP-conjugated antimouse antibodies were obtained from GE Healthcare, Biosciences. All other chemicals were of analytical grade and were purchased from Sigma Chemical Co., Merck/VWR, or J.T. Baker (Phillipsburg, NJ).
Preparation of total cell extracts, isolation of raft fractions. Semi-confluent cells were grown for $18 \mathrm{~h}$ in medium with serum or, when indicated, were rinsed twice and were grown in serum-free medium. Afterwards the cells were stimulated with $2 \mu \mathrm{g} / \mathrm{ml}$ of mouse L243 antibody direct against a conformational epitope of the HLA-DR molecules or with $2 \mu \mathrm{g} / \mathrm{ml}$ of isotypematched control antibody at $37^{\circ} \mathrm{C}$ from $15 \mathrm{~min}$ to $1 \mathrm{~h}$. To alter the cholesterol content of the plasma membrane, the cells were treated with $10 \mathrm{mM}$ of $\mathrm{M} \beta \mathrm{CD}$ for $15 \mathrm{~min}$ at $37^{\circ} \mathrm{C}$ before antibody stimulation. To obtain total cell extracts, the cells were lysed on ice for $30 \mathrm{~min}$ in lysis buffer $(50 \mathrm{mM}$ Tris- $\mathrm{HCl}$ $\mathrm{pH} 7.4,150 \mathrm{mM} \mathrm{NaCl}, 1 \%$ Triton $\mathrm{X}-100,1 \mathrm{mM}$ EDTA) containing an anti-proteases cocktail ( $3 \mu \mathrm{g} / \mathrm{ml}$ aprotinin, $4 \mathrm{mM}$ PMSF, $1 \mu \mathrm{g} / \mathrm{ml}$ leupeptin) and then cleared of cellular debris by centrifugation at $14,000 \mathrm{x}$ at $4^{\circ} \mathrm{C}$ for $30 \mathrm{~min}$. In signalling experiments the lysis buffer was supplemented with an antiphosphatase cocktail ( $1 \mathrm{mM} \mathrm{Na}_{3} \mathrm{VO}_{4}$ and $50 \mathrm{mM} \mathrm{NaF}$ ). The proteins concentration of the supernatants was determined using the Bradford protein assay (Bio-Rad Laboratories $\mathrm{GmbH}$, München, Germany). Otherwise, to isolate the raft fractions (36), the cells were lysed in MBS buffer $(25 \mathrm{mM}$ MES, 2 mM EDTA pH 8.0 and $150 \mathrm{mM} \mathrm{NaCl}$ ) containing $1 \%$ Triton X-100 and anti-proteases cocktail for $30 \mathrm{~min}$ on ice. The lysates mixed with an equal volume of $85 \%$ sucrose $(w / v)$ in MBS buffer, were placed at the bottom of a polycarbonate ultracentrifuge tube (Beckman Instruments, Palo Alto, CA), overlaid with $2 \mathrm{ml}$ of $35 \%$ sucrose and $1 \mathrm{ml}$ of $5 \%$ sucrose in MBS buffer containing $2 \mathrm{mM}$ EDTA pH 8.0 and anti-proteases cocktail and were centrifuged at $100,000 \mathrm{x}$ g for $20 \mathrm{~h}$ at $4^{\circ} \mathrm{C}$ in a SW55Ti rotor (Beckman Instruments). In SDS-stability experiments, the total cell extracts as well as the raft fractions enriched by centrifugation at $14,000 \mathrm{x} \mathrm{g}$ for $30 \mathrm{~min}$ at $4^{\circ} \mathrm{C}$, were resuspended in Laemmli buffer containing $2.5 \%$ $\beta$-mercaptoethanol and heated at $95^{\circ} \mathrm{C}$ for $7 \mathrm{~min}$ in order to dissociate the MHC class II heterodimers; otherwise were incubated at room temperature under non-reducing conditions in order to detect the MHC class II heterodimers. The isolated raft fractions of cells pre-treated with $\mathrm{M} \beta \mathrm{CD}$ before antibody stimulation, were enriched by centrifugation at $14,000 \mathrm{x} \mathrm{g}$ for $30 \mathrm{~min}$ at $4^{\circ} \mathrm{C}$.

Western blot analysis. Total cell extracts (40-60 $\mu \mathrm{g})$ or $28 \mu \mathrm{l}$ of fractions from 1 to 4 and $14 \mu \mathrm{l}$ of fractions from 5 to 9 were resolved on sodium dodecyl sulfate-polyacrylamide gel electrophoresis (SDS-PAGE) and absorbed to nitrocellulose membrane (Hybond ECL, GE Healthcare, Biosciences). Blocking was performed for $2 \mathrm{~h}$ at room temperature in phosphate-buffered saline (PBS)-Tween buffer containing $3 \%$ bovine serum albumin (BSA) and $0.02 \% \mathrm{NaN}_{3}$. The membranes incubation with primary antibodies $(5 \mu \mathrm{g} / \mathrm{ml}$ of the monoclonal anti-HLA-DR- $\alpha$-chain, DA6.147 or 1:1,000 of the anti-caveolin, anti-pJNK and anti-h- $\beta$-actin) was overnight at $4^{\circ} \mathrm{C}$ in PBS-Tween buffer containing $1 \%$ BSA. Therefore, the membranes were incubated for $50 \mathrm{~min}$ at room temperature with HRP-conjugated anti-rabbit or HRP-conjugated anti-mouse secondary antibodies in PBS-Tween buffer containing $0.25 \%$ BSA. Immunoreactive bands were visualized using an enhanced chemiluminescence kit (SuperSignal West Pico Chemiluminescent Substrate, Pierce). 
A L243

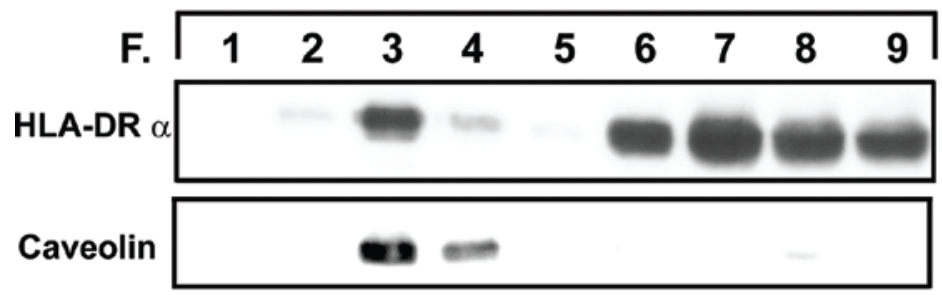

B L243

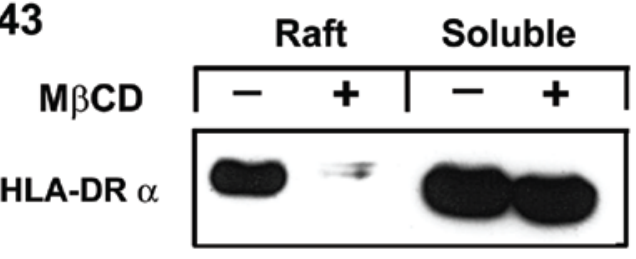

\section{CTX FITC L243 TRITC Overlay}

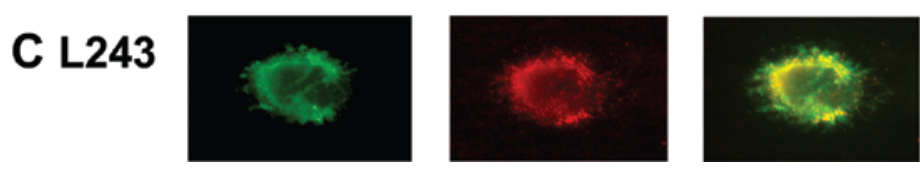

Figure 1. HLA-DR localization in the lipid raft of human A375 melanoma cells. Melanoma cells were stimulated for 30 min at $37^{\circ} \mathrm{C}$ with a specific antibody that mimics the interaction of TCR with class II molecules (L243) (A-C) and the lipid raft compartments were isolated through discontinuous sucrose gradient (A and B). (A) The low density fractions (from F2 to F4) and the high density fractions (from F6 to F9) were resolved on 10\% polyacrylamide gels and analyzed through Western blotting using an antibody directed against the $\alpha$ chain of the HLA-DR molecules (upper panel). As a positive control of the raft compartments the localization of the caveolin was also analyzed (lower panel). (B) The melanoma cells were treated for 15 min with methyl- $\beta$ cyclodextrin (MBCD) before the L243 antibody stimulation. The isolated raft fractions were enriched by centrifugation, then resolved on $10 \%$ polyacrylamide gels and analyzed using an antibody direct against the HLA-DR $\alpha$ chain. The disruption of the raft integrity before the L243 antibody stimulation with the methyl- $\beta$-cyclodextrin $(\mathrm{M} \beta \mathrm{CD})$ treatment prevents the recruitment of the HLA-DR molecules in the lipid raft compartments of stimulated melanoma cells $(+$ $\mathrm{M} \beta \mathrm{CD}$, raft). (C) The co-localization of HLA-DR molecules and raft-specific ganglioside GM1 was visualized by IF experiments. In particular, the melanoma cells were stimulated with L243 antibody $(10 \mu \mathrm{g} / \mathrm{ml})$ for $20 \mathrm{~min}$ at $4^{\circ} \mathrm{C}$ followed by the TRITC-labelled (L243 TRITC and overlay) anti-mouse antibody and the FITC-conjugated cholera toxin B (CTX FITC and overlay) incubations and then fixed with paraformaldehyde. Images were acquired with a Zeiss Axioskop 2 Plus microscope using a $\times 40$ objective. The results are representative of three independent experiments.

Immunofluorescence microscopy. The cells grown on coverslips, were stimulated with either the anti-HLA-DR (L243) or the isotype-matched control antibodies $(10 \mu \mathrm{g} / \mathrm{ml})$ for $5 \mathrm{~min}$ at $4^{\circ} \mathrm{C}$ and fixed with $1 \%$ glutaraldehyde in PBS for $1 \mathrm{~h}$ at $4^{\circ} \mathrm{C}$. Therefore, the cells were incubated with $50 \mathrm{mM} \mathrm{NH}_{4} \mathrm{Cl}$ in PBS followed by blocking and per-meabilization with $0.2 \%$ Triton X-100 and 1\% BSA in PBS for $30 \mathrm{~min}$ at room temperature. The cells were incubated with the primary antibody (L243 diluted 1:20) for $1 \mathrm{~h}$ at room temperature followed by FITC-labeled anti-mouse IgG secondary antibody incubation for $50 \mathrm{~min}$ at room temperature in PBS containing $0.2 \%$ Triton X-100 and 1\% BSA. The cells were washed 3 times in PBS with $0.2 \%$ Triton X-100 after each incubation and then mounted with glycerol. Images were acquired with an Olympus BX 50 fluorescent microscope using a x40 and a x100 oil immersion objectives. Otherwise the cells were fixed for $30 \mathrm{~min}$ at $4^{\circ} \mathrm{C}$ with $1 \%$ paraformaldehyde after stimulation at $4^{\circ} \mathrm{C}$ with $\mathrm{L} 243$ antibody for $20 \mathrm{~min}(10 \mu \mathrm{g} / \mathrm{ml})$, followed by TRITC-labeled anti-mouse IgG secondary antibody incubation for 30 min at $37^{\circ} \mathrm{C}(1: 600)$ and cholera-toxin B FITC-labeled $(1: 150)$ incubation for $30 \mathrm{~min}$ at $4^{\circ} \mathrm{C}$. The antibodies as well as the choleratoxin B FITC-labeled were diluted in PBS containing $1 \%$ BSA; the cells were washed 3 times in PBS after each incubation and then mounted with glycerol. Images were acquired with a Zeiss Axioskop 2 Plus microscope using a x40 objective and recorded with a digital camera system.

\section{Results}

The engagement of the HLA-DR molecules induces their recruitment into the lipid raft compartments of A375 melanoma cells. In order to understand the role played by the class II molecules in melanoma cells to frustrate an effective antitumour response, we studied the localization of HLA-DR molecules in cholesterol and glycosphingolipid-enriched membrane microdomains, or rafts, which are membrane domains where signalling complexes assemble (30). Therefore, the MHC class II constitutively expressing A375 melanoma cells were stimulated with a specific anti-HLA-DR antibody (L243) that mimics the TCR interaction with the class II molecules, or with the mouse isotype control IgG2a antibody for $30 \mathrm{~min}$ at $37^{\circ} \mathrm{C}$ and the lipid rafts were isolated through a discontinuous sucrose gradient (36). The results of these experiments showed the localization of the HLA-DR molecules on the low density fractions (Fig. 1A: F. 2, 3 and 4, upper panel) containing the lipid raft compartments after L243 stimulation of melanoma cells. The results obtained showed also that only a slight amount of the HLA-DR molecules was constitutively 
localized on the low density fractions (Fig. 2A: IgG2a, F. 2, 3 and 4, upper panel), while a significant recruitment of the HLA-DR molecules in these fractions (Fig. 2A: L243, F. 2, 3 and 4, upper panel) was observed after L243 stimulation of melanoma cells. As a positive control of the raft compartments, the localization of the caveolin on the isolated fractions was also analysed (37) (Figs. 1A and 2A lower panels). Moreover, the analysis of all the collected fractions showed also the HLA-DR molecule localization in the high density fractions (F. 6, 7, 8, 9) containing soluble proteins (Fig. 1A upper panel).

To verify the localization of the HLA-DR molecules on the fractions containing the lipid rafts, the melanoma cells were pre-treated for $15 \mathrm{~min}$ at $37^{\circ} \mathrm{C}$ with methyl- $\beta$-cyclodextrin $(\mathrm{M} \beta \mathrm{CD})$ that disrupts the raft integrity by cholesterol depletion before the L243 antibody stimulation. The marked diminution of HLA-DR molecules on the low density fractions (Fig. 1B: raft, + $\mathrm{M} \beta \mathrm{CD}$ ) obtained under these conditions showed that the cholesterol depletion prevents the recruitment of HLA-DR molecules in the rafts of stimulated melanoma cells (Fig. 1B: + $\mathrm{M} \beta C D$ versus - $\mathrm{M} \beta C D$ ). Moreover, in order to acquire evidence of the MHC class II association with cholesterol and sphingolipid-rich membranes we analyzed on L243 stimulated A375 melanoma cells the co-patching of MHC class II molecules with the ganglioside GM1 that can be visualized through FITC-conjugated cholera toxin B staining and immunofluorescence experiments. As shown in Fig. 1C, the clusters of HLA-DR molecules (Fig. 1C: L243 TRITC) are co-localized with patched GM1 (Fig. 1C: CTX FITC and overlay). Therefore, using this qualitative method, we demonstrated the colocalization of the HLA-DR molecules with the lipid raft marker GM1 (Fig. 1C: overlay). Furthermore, the immunofluorescence experiments were used to analyse the HLA-DR localization in A375 melanoma cells and thus validate the results obtained (Fig. 2B). These experiments showed that the L243 stimulation of melanoma cells led to a significant recruitment of HLA-DR molecules in patches of plasma membrane that are larger than in unstimulated cells (Fig. 2B: L243 versus IgG2a). Therefore, these results indicated that the HLA-DR recruitment into the lipid raft compartments of melanoma cells is dependent on its engagement. The consequence of the MHC class II recruitment in lipid rafts could be the activation of some signalling pathways.

The HLA-DR-peptide complexes are also localized into the lipid raft fractions of A375 melanoma cells. In light of the knowledge that the processed antigen stabilizes the MHC class II $\alpha \beta$ heterodimers in an SDS solution at room temperature and during SDS-PAGE (38), we studied the function of HLA-DR molecules in total cell extracts of unstimulated (Fig. 3A: NS) and L243 stimulated cells (Fig. 3A: L243, for $15 \mathrm{~min}, 30 \mathrm{~min}, 1 \mathrm{~h}$ ) as well as in the raft fractions of L243 stimulated melanoma cells (Fig. 3B) using SDS stability assay. In non-denatured samples of unstimulated or L243 stimulated total cell extracts (Fig. 3A: ND) as well as of raft fractions (Fig. 3B: ND) of stimulated melanoma cells, the processed antigen stabilizes the HLA-DR $\alpha \beta$ heterodimers $(\alpha \beta)$. Under these conditions the HLA-DR heterodimers that do not contain strongly bound peptide or that are not associated with peptide (Fig. 3) were dissociated (HLA-DR- $\alpha$ ). The SDS-stable

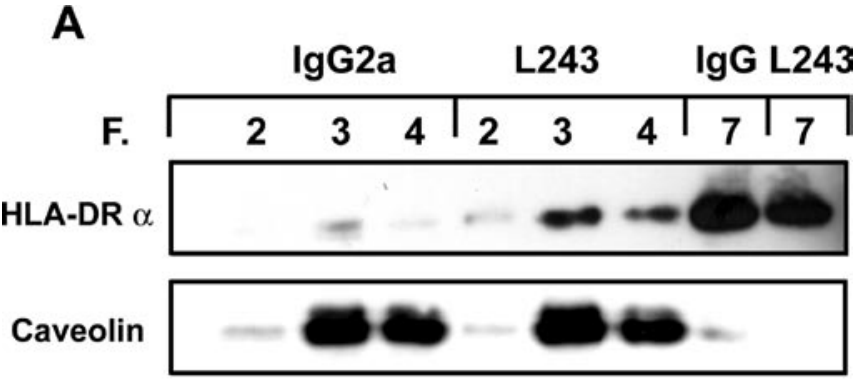

B
IgG2a

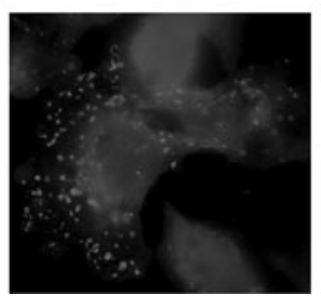

L243

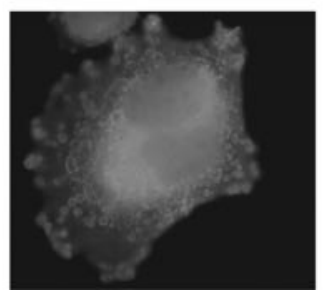

Figure 2. HLA-DR recruitment in lipid raft compartments of L243 stimulated melanoma cells. (A) The A375 melanoma cells were stimulated for $30 \mathrm{~min}$ at $37^{\circ} \mathrm{C}$ with the $\mathrm{L} 243$ antibody or with a mouse isotype control IgG2a antibody (IgG2a) and the raft fractions were isolated. This experiment showed that the HLA-DR molecules were recruited in the fractions containing the lipid rafts (from F2 to F4, upper panel) of stimulated melanoma cells (L243), while only a slight amount of the HLA-DR molecules was constitutively (IgG2a) localized in these fractions (from F2 to F4, upper panel). As a positive control of the raft compartments, the localization of the caveolin on the lipid raft fractions was also analyzed (lower panel). (B) A375 melanoma cells were stimulated with $10 \mu \mathrm{g} / \mathrm{ml}$ of mouse isotype control IgG2a antibody or with L243 antibody for $5 \mathrm{~min}$ at $37^{\circ} \mathrm{C}$ and fixed with glutaraldehyde. The localization of the HLA-DR molecules was analysed by IF experiments using the L243 antibody and the FITC-labelled (IgG2a and L243) anti-mouse antibody. Images were acquired with an Olympus BX 50 fluorescent microscope using x100 oil immersion objective. The stimulation of the melanoma cells led to a significant recruitment of the HLA-DR molecules in larger patches of plasma membranes (L243 versus IgG2a). The results are representative of three independent experiments.

HLA-DR heterodimers were dissociated by boiling into free $\alpha$ (Fig. 3A and B: D) and $\beta$ chains (data not shown). The results of these experiments showed that the HLA-DR molecules assembled in the $\alpha \beta$-peptide complexes are also localized in the raft fractions of stimulated melanoma cells, where they can interact with the $\mathrm{T}$ cell receptor of $\mathrm{CD} 4^{+} \mathrm{T}$ cells.

Signalling of the HLA-DR molecules in stimulated melanoma cells. The physical association of the engaged MHC class II molecules with cell surface receptors of immune cells has been reported to facilitate the activation of different intracellular signalling cascades providing another level of signal modulation $(39,40)$. We analysed in melanoma cells, the consequences of HLA-DR molecule engagement on the activation of the MAPK family members. The total cell extracts of unstimulated (NS) and L243 stimulated (15 min, $30 \mathrm{~min}$ and $1 \mathrm{~h}$ ) A375 melanoma cells grown with or without serum were analysed through Western blot experiments. The results obtained showed an enhanced JNK, but not p38 (data not shown) phosphorylation as a consequence of the HLA-DR engagement (Fig. 4B: L243, $15 \mathrm{~min}, 30 \mathrm{~min}, 1 \mathrm{~h}$, upper panel). Interestingly, 
A Total

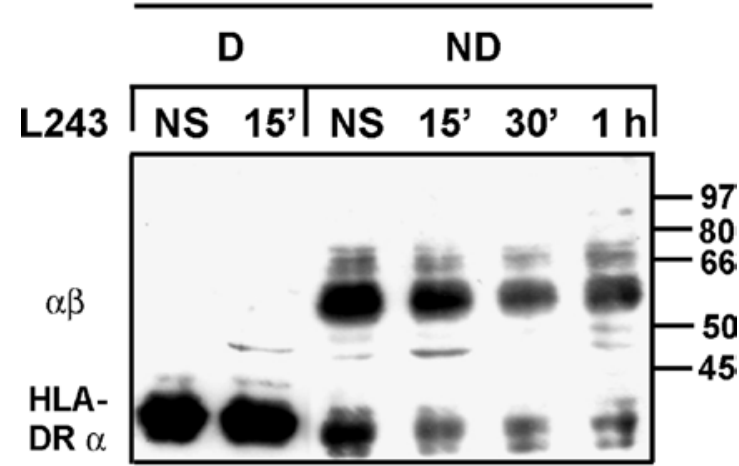

B L243

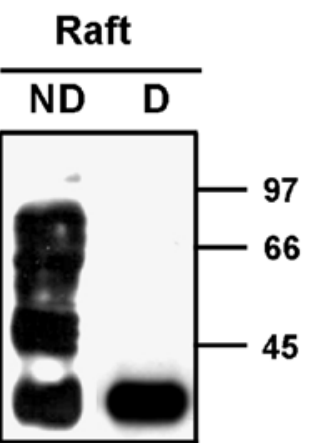

Figure 3. SDS-stability assay of HLA-DR molecules in total cell extracts and in the raft fractions of stimulated melanoma cells. (A) Sixty $\mu \mathrm{g}$ of unstimulated (NS) and L243 stimulated (15', 30' and $1 \mathrm{~h}$ ) melanoma cell extracts as well as the fractions containing the raft compartments enriched by centrifugation (B) of L243 stimulated melanoma cells were heated under reducing conditions (D) or incubated at room temperature under nonreducing conditions (ND) and were resolved on $10 \%$ polyacrylamide gels. (A and B) In non-denatured (ND) samples the antibody directed against the $\alpha$ chain of the HLA-DR molecules detects SDS-stable $\alpha \beta$-peptide complexes $(\alpha \beta)$. SDS-stable HLA-DR heterodimers were dissociated by boiling (D) into free $\alpha$ chain (HLA-DR $\alpha$ ). The results are representative of three independent experiments.

in A375 melanoma cells grown without serum, the activation of JNK phosphorylation was evident only after $1 \mathrm{~h}$ of L243 stimulation (Fig. 4B: W/O serum), although there is no difference in the amount of MHC class II recruited in the raft fractions of L243 stimulated melanoma cells grown with or without serum (Fig. 4A: F. 2, 3 and 4 with serum versus w/o serum, upper panel). To ensure that equal amounts of total cell extracts and low density fractions were used in each sample, Western blot experiments were performed using respectively an antibody specific for the $\beta$-actin (Fig. 4B lower panel) and for the caveolin (Fig. 4A lower panel). In conclusion, these results indicate that the HLA-DR engagement in melanoma cells is associated with JNK activation suggesting a nonsecondary role for MHC class II molecules in the activation of signalling pathways.

\section{Discussion}

The cell membranes display a remarkable complexity of lipids and protein components that are able to segregate laterally underling the raft model of membrane compartmentalization.
A With serum WIO serum

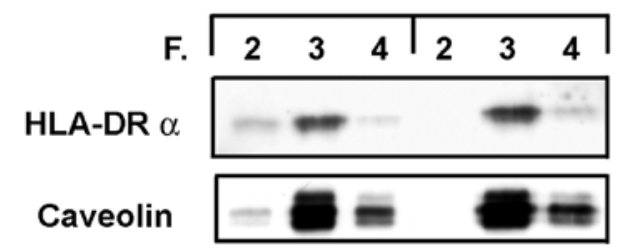

B

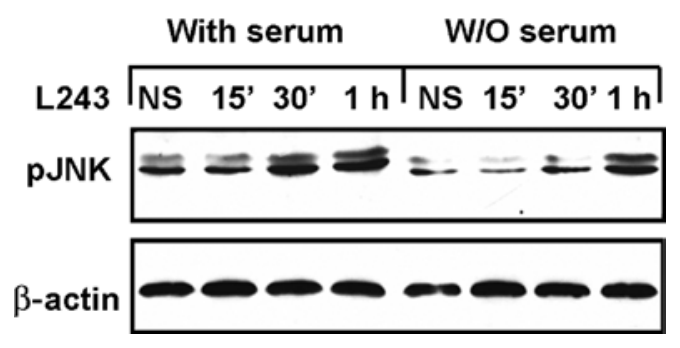

Figure 4. HLA-DR signalling in melanoma cells. Melanoma cells grown with or without $(\mathrm{W} / \mathrm{O})$ serum were stimulated with the L243 antibody (A) and the lipid raft compartments were isolated. The low density fractions from F2 to F4 were resolved on $10 \%$ polyacrylamide gel and analyzed through Western blotting using an antibody directed against the $\alpha$ chain of the HLA-DR molecules (upper panel). Equal amount of proteins in the low density fractions was confirmed by the analysis of the caveolin (lower panel). (B) Unstimulated (NS) and stimulated (L243, 15', 30' and $1 \mathrm{~h}$ ) extracts $(60 \mu \mathrm{g})$ of melanoma cells grown with or without (W/O) serum were resolved on $10 \%$ polyacrylamide gel and analysed using an antibody directed against the phosphorylated form of JNK (upper panel). The equal protein loading was confirmed by the analysis of the $\beta$-actin expression (lower panel). The increasing phosphorylation of JNK is a consequence of HLA-DR molecule engagement. The results are representative of three independent experiments.

The lipid rafts are enriched in freely diffusing assemblies of sphingolipids, cholesterol and proteins that can be stabilized to coalesce in transient signalling platforms (30). Indeed the interaction between the MHC-II-peptide complexes expressed on APCs and the antigen-specific TCRs is required for T cell activation (41). Therefore, in light of the knowledge that $\mathrm{CD}^{+} \mathrm{T}$ cells are sensitive to small amounts of MHC-IIantigen complexes, it has been proposed that the lipid raft clustering of class II molecules is crucial to locally increase the concentration of these molecules in APC and facilitate the TCR-MHC-II-peptide complexes interaction (42). Stable antigen-dependent $\mathrm{T}$ cells interactions with tumour cells have been shown by in vitro (43) and intravital studies (44), but in melanoma, notwithstanding the $\mathrm{CD}^{+} \mathrm{T}$ cells can recognize MHC-II-antigens complexes, tumour-reactive $\mathrm{T}$ cells are associated with in vivo tumour regression in only a modest number of patients (22). Instead the constitutive MHC class II expression in melanoma is associated with disease progression (13-19). Therefore, to shed more light on the mechanisms of melanoma immune escape, we stimulated a MHC class II constitutive expressing melanoma cell line with a specific antibody that mimics the interaction of TCR with class II molecules. In these experiments we showed the recruitment of HLA-DR molecules in the lipid raft compartments of stimulated melanoma cells through discontinuous sucrose 
gradient as well as more qualitative immunofluorescence experiments (Figs. 1 and 2). Moreover, since the antigen-processing pathway must to be functional for TCR-MHC class II molecule interaction, we studied the antigen presentation of class II molecules in this melanoma cell line. We showed that a high amount of SDS-stable HLA-DR-peptide complexes is recruited in lipid rafts of stimulated melanoma cells (Fig. 3). Therefore, in light of the results reported, we speculate that the lipid rafts recruitment of MHC class II molecules and the antigen presentation by these molecules compartmentalized could increase both the interaction between melanoma and $\mathrm{T}$ cells and their stability. In addition, notwithstanding that the presentation of antigens by melanoma cells is not directly correlated to clinical regression (22), the melanoma cells could act as APC for $\mathrm{CD}^{+} \mathrm{T}$ cells that recognize class II antigens. The interaction of MHC-II-peptide complex with cell surface receptor of $\mathrm{T}$ cells has been shown to modulate the activation of signalling pathways in T cells and APC, which is greatly enhanced by the class II compartmentalization in lipid rafts (27-29). Therefore, our hypothesis was that the lipid raft clustering of class II molecules could activate in melanoma cells some signalling pathways to escape the control of immune cells. Through immunofluorescence experiments we showed that the class II engagement on melanoma cells led to HLA-DR molecule recruitment in patches of plasma membrane that, in L243 stimulated cells are larger than in unstimulated cells. These results suggested that the consequence of the MHC class II recruitment in lipid rafts could be the coalescence of membrane domains and the formation of signalling platforms for the activation of signalling pathways. We analysed the signalling mediated by class II molecules and we showed the activation of JNK member of MAPK family following the MHC class II engagement (Fig. 4). JNK is crucial in the regulation of cell proliferation, cell survival, cell death, DNA repair and metabolism and the activation of JNK has been shown to either promote or eradicate tumours depending on the cellular context $(45,46)$. The critical role of this kinase in melanoma growth and progression as well as its role in melanoma immune escape through the repression of melanocytedifferentiation gene expression in cells treated with some inflammatory cytokines has been previously reported $(47,48)$. Taken together, our studies suggest a model in which the stimulation of melanoma cells via MHC class II molecules and the consequent redistribution of class II molecules into areas of lipid raft microdomains, provide foci of signalling that could be useful for melanoma cells to frustrate an effective anti-tumour response as well the activation of JNK thus modulating multiple cell invasion-associated gene expression $(49,50)$. The molecular mechanisms by which class II molecules clustered in membrane lipid rafts of melanoma cells can cross-link $\mathrm{T}$ cell receptors and possibly inhibit the interacting $\mathrm{T}$ cells require further study.

\section{Acknowledgements}

We wish to thank Professor Maria Teresa Musmeci (Dipartimento di Ecologia, Università degli Studi di Palermo) for her expert technical assistance in fluorescence microscopy and microphotography, for generously providing several reagents and for helpful discussions. We also thank Dr F. Zito and Dr C. Cascio (Istituto di Biomedicina e Immunologia Molecolare, Consiglio Nazionale delle Ricerche) for their useful technical suggestions and for helpful discussions and Professor C. Alcaide-Loridan (Regulation des Reponses Immunitaires, Institut Jacques Monod, Universitè Paris 7, Paris, France), for providing melanoma cell lines and anti-HLA-DR antibodies.

\section{References}

1. Jemal A, Siegel R, Xu J and Ward E: Cancer statistics, 2010. CA Cancer J Clin 60: 277-300, 2010.

2. Gray-Schopfer V, Wellbrock C and Marais R: Melanoma biology and new targeted therapy. Nature 445: 851-857, 2007.

3. Miller AJ and Mihm MC Jr: Melanoma. N Engl J Med 355: 51-65, 2006.

4. Lee CC, Faries MB, Wanek LA and Morton DL: Improved survival for stage IV melanoma from an unknown primary site. J Clin Oncol 27: 3489-3495, 2009.

5. Nuber N, Curioni-Fontecedro A, Matter C, Soldini D, Tiercy JM, von Boehmer L, Moch H, Dummer R, Knuth A and van den Broek M: Fine analysis of spontaneous MAGE-C1/CT7-specific immunity in melanoma patients. Proc Natl Acad Sci USA 107: 15187-15192, 2010.

6. Boon T, Coulie PG, van den Eynde BJ and van der Bruggen P: Human $\mathrm{T}$ cell responses against melanoma. Annu Rev Immunol 24: 175-208, 2006.

7. Quaglino P, Marenco F, Osella-Abate S, Cappello N, Ortoncelli M, Salomone B, Fierro MT, Savoia P and Bernengo MG: Vitiligo is an independent favourable prognostic factor in stage III and IV metastatic melanoma patients: results from a single-institution hospital-based observational cohort study. Ann Oncol 21: 409-414, 2010.

8. Uchi H, Stan R, Turk MJ, Engelhorn ME, Rizzuto GA, Goldberg SM, Wolchok JD and Houghton AN: Unraveling the complex relationship between cancer immunity and autoimmunity: lessons from melanoma and vitiligo. Adv Immunol 90: 215-241, 2006.

9. Agarwala SS: Novel immunotherapies as potential therapeutic partners for traditional or targeted agents: cy totoxic T-lymphocyte antigen-4 blockade in advanced melanoma. Melanoma Res 20: $1-10,2010$.

10. Dranoff G: Targets of protective tumor immunity. Ann NY Acad Sci 1174: 74-80, 2009.

11. Fang L, Lonsdorf AS and Hwang ST: Immunotherapy for advanced melanoma. J Invest Dermatol 128: 2596-2605, 2008.

12. Kirkwood JM, Tarhini AA, Panelli MC, Moschos SJ, Zarour HM, Butterfield LH and Gogas HJ: Next generation of immunotherapy for melanoma. J Clin Oncol 26: 3445-3455, 2008.

13. Campoli $\mathrm{M}$ and Ferrone $\mathrm{S}$ : A fresh look at an old story: revisiting HLA class II antigen expression by melanoma cells. Expert Rev Dermatol 1: 737-755, 2006.

14. Rodriguez T, Mendez R, Del Campo A, Aptsiauri N, Martin J, Orozco G, Pawelec G, Schadendorf D, Ruiz-Cabello F and Garrido F: Patterns of constitutive and IFN-gamma inducible expression of HLA class II molecules in human melanoma cell lines. Immunogenetics 59: 123-133, 2007.

15. Deffrennes V, Vedrenne J, Stolzenberg MC, Piskurich J, Barbieri G, Ting JP, Charron D and Alcaide-Loridan C: Constitutive expression of MHC class II genes in melanoma cell lines results from the transcription of class II transactivator abnormally initiated from its B cell-specific promoter. J Immunol 167: 98-106, 2001.

16. Elder DE, Rodeck U, Thurin J, Cardillo F, Clark WH, Stewart R and Herlyn M: Antigenic profile of tumor progression stages in human melanocytic nevi and melanomas. Cancer Res 49: 5091-5096, 1989.

17. Bernsen MR, Hakansson L, Gustafsson B, Krysander L, Rettrup B, Ruiter D and Hakansson A: On the biological relevance of MHC class II and B7 expression by tumour cells in melanoma metastases. Br J Cancer 88: 424-431, 2003.

18. Barbieri G, Deffrennes V, Prod'homme T, Vedrenne J, Baton F, Cortes C, Fischer A, Bono MR, Lisowska-Grospierre B, Charron D and Alcaide-Loridan C: Isoforms of the class II transactivator protein. Int Immunol 14: 1-10, 2002. 
19. Baton F, Deruyffelaere C, Chapin M, Prod'homme T, Charron D, Al-Daccak R and Alcaide-Loridan C: Class II transactivator (CIITA) isoform expression and activity in melanoma. Melanoma Res 14: 453-461, 2004.

20. Campoli M and Ferrone S: HLA antigen changes in malignant cells: epigenetic mechanisms and biologic significance. Oncogene 27: 5869-5885, 2008.

21. Li Y, Depontieu FR, Sidney J, Salay TM, Engelhard VH, Hunt DF, Sette A, Topalian SL and Mariuzza RA: Structural basis for the presentation of tumor-associated MHC class II-restricted phosphopeptides to $\mathrm{CD}^{+}{ }^{+} \mathrm{T}$ cells. J Mol Biol 399: 596-603, 2010.

22. Robbins PF, El-Gamil M, Li YF, Zeng G, Dudley M and Rosenberg SA: Multiple HLA class II-restricted melanocyte differentiation antigens are recognized by tumor-infiltrating lymphocytes from a patient with melanoma. J Immunol 169: 6036-6047, 2002.

23. Cebon J, Gedye C, John T and Davis ID: Immunotherapy of advanced or metastatic melanoma. Clin Adv Hematol Oncol 5: 994-1006, 2007.

24. Glimcher LH and Kara CJ: Sequences and factors: a guide to MHC class II transcription. Ann Rev Immunol 10: 13-50, 1992.

25. Tsujisaki M, Igarashi M, Sakaguchi K, Eisinger M, Herlyn M and Ferrone S: Immunochemical and functional analysis of HLA class II antigens induced by recombinant interferon on normal epidermal melanocytes. J Immunol 138: 1310-1316, 1987.

26. Al-Daccak R, Mooney N and Charron D: MHC class II signaling in antigen-presenting cells. Curr Opin Immunol 16: 108-113, 2004

27. Anderson HA, Hiltbold EM and Roche PA: Concentration of MHC class II molecules in lipid rafts facilitates antigen presentation. Nat Immunol 1: 156-162, 2000.

28. Khandelwal S and Roche PA: Distinct MHC class II molecules are associated on the dendritic cell surface in cholesterol-dependent membrane microdomains. J Biol Chem 285: 35303-35310, 2010.

29. Poloso NJ and Roche PA: Association of MHC class II-peptide complexes with plasma membrane lipid microdomains. Curr Opin Immunol 16: 103-107, 2004.

30. Lingwood D and Simons K: Lipid rafts as a membrane-organizing principle. Science 327: 46-50, 2010.

31. Huby RD, Dearman RJ and Kimber I: Intracellular phosphotyrosine induction by major histocompatibility complex class II requires co-aggregation with membrane rafts. J Biol Chem 274: 22591-22596, 1999

32. Becart S, Setterblad N, Ostrand-Rosenberg S, Ono SJ, Charron D and Mooney N: Intracytoplasmic domains of MHC class II molecules are essential for lipid-raft-dependent signaling. J Cell Sci 116: 2565-2575, 2003

33. Lampson LA and Levy R: Two populations of Ia-like molecules on a human B cell line. J Immunol 125: 293-299, 1980.

34. Giard DJ, Aaronson SA, Todaro GJ, Arnstein P, Kersey JH, Dosik $\mathrm{H}$ and Parks WP: In vitro cultivation of human tumors: establishment of cell lines derived from a series of solid tumors. J Natl Cancer Inst 51: 1417-1423, 1973.

35. Guy K, Van Heyningen V, Cohen BB, Deane DL and Steel CM: Differential expression and serologically distinct subpopulations of human Ia antigens detected with monoclonal antibodies to Ia alpha and beta chains. Eur J Immunol 12: 942-948, 1982.
36. Xavier R, Brennan T, Li Q, McCormack C and Seed B: Membrane compartmentation is required for efficient $\mathrm{T}$ cell activation. Immunity 8: 723-732, 1998 .

37. Sargiacomo M, Sudol M, Tang Z and Lisanti MP: Signal transducing molecules and glycosyl-phosphatidylinositol-linked proteins form a caveolin-rich insoluble complex in MDCK cells. J Cell Biol 122: 789-807, 1993.

38. Springer TA, Kaufman JF, Siddoway LA, Mann DL and Strominger JL: Purification of HLA-linked B lymphocyte alloantigens in immunologically active form by preparative sodium dodecyl sulfate-gel electrophoresis and studies on their subunit association. J Biol Chem 252: 6201-6207, 1977.

39. Leveille C, Castaigne JG, Charron D and Al-Daccak R: MHC class II isotype-specific signaling complex on human B cells. Eur J Immunol 32: 2282-2291, 2002.

40. Doisne JM, Castaigne JG, Deruyffelaere C, Dieu-Nosjean MC, Chamot C, Alcaide-Loridan C, Charron D and Al-Daccak R: The context of HLA-DR/CD18 complex in the plasma membrane governs HLA-DR-derived signals in activated monocytes. Mol Immunol 45: 709-718, 2008.

41. Dustin ML: The cellular context of $\mathrm{T}$ cell signaling. Immunity 30: 482-492, 2009.

42. Komaniwa S, Hayashi H, Kawamoto $H$, Sato SB, Ikawa T, Katsura $\mathrm{Y}$ and Udaka K: Lipid-mediated presentation of MHC class II molecules guides thymocytes to the CD4 lineage. Eur J Immunol 39: 96-112, 2009.

43. Zarour HM, Kirkwood JM, Kierstead LS, Herr W, Brusic V, Slingluff CL, Sidney J, Sette A and Storkus WJ: Melan-A/ MART-1(51-73) represents an immunogenic HLA-DR4-restricted epitope recognized by melanoma-reactive CD4(+) T cells. Proc Natl Acad Sci USA 97: 400-405, 2000.

44. Mrass P, Takano H, Ng LG, Daxini S, Lasaro MO, Iparraguirre A, Cavanagh LL, von Andrian UH, Ertl HC, Haydon PG and Weninger W: Random migration precedes stable target cell interactions of tumor-infiltrating T cells. J Exp Med 203: 2749-2761, 2006.

45. Shaulian E: AP-1 - the Jun proteins: oncogenes or tumor suppressors in disguise? Cell Signal 22: 894-899, 2010.

46. Kennedy NJ and Davis RJ: Role of JNK in tumor development. Cell Cycle 2: 199-201, 2003.

47. Cohen C, Zavala-Pompa A, Sequeira JH, Shoji M, Sexton DG, Cotsonis G, Cerimele F, Govindarajan B, Macaron N and Arbiser JL: Mitogen-actived protein kinase activation is an early event in melanoma progression. Clin Cancer Res 8: 3728-3733, 2002.

48. Kholmanskikh O, van Baren N, Brasseur F, Ottaviani S, Vanacker J, Arts N, van der Bruggen P, Coulie P and De Plaen E: Interleukins 1alpha and 1beta secreted by some melanoma cell lines strongly reduce expression of MITF-M and melanocyte differentiation antigens. Int J Cancer 127: 1625-1636, 2010.

49. Mitra SK and Schlaepfer DD: Integrin-regulated FAK-Src signaling in normal and cancer cells. Curr Opin Cell Biol 18: 516-523, 2006

50. Ozanne BW, McGarry L, Spence HJ, Johnston I, Winnie J, Meagher L and Stapleton G: Transcriptional regulation of cell invasion: AP-1 regulation of a multigenic invasion programme. Eur J Cancer 36: 1640-1648, 2000. 